\title{
0 paradoxo da política de segurança pública: Estado, PCC e a gestão da violência na cidade de São Paulo
}

\author{
Denis Delgado Santos, Domenico Rodrigues Simião Reis Jorge, Eduardo Rumenig de Souza ${ }^{1}$
}

\begin{abstract}
Resumo: 0 presente artigo explora a contribuição do Estado para a emergência e consolidação do PCC (Primeiro Comando da Capital), e de que forma essa facção criminosa atua na gestão da violência em São Paulo, influindo na queda da taxa de homicídios da capital paulista. Argumenta-se que a política de encarceramento em massa - em vigor no estado de São Paulo desde meados dos anos 1990 - constitui um paradoxo da política de segurança pública: se por um lado ela reduz o número de mortes violentas ao retirar de circulação um contingente expressivo de criminosos; por outro, acaba fortalecendo a criminalidade organizada ao recolher criminosos avulsos das ruas e os colocar em contato com facções dentro dos presídios, que se estabelecem como poder político-jurídico local.
\end{abstract}

Palavras-chave: Estado, PCC, facção criminosa, violência, São Paulo.

\section{Introdução}

No Brasil a violência urbana ocupa um espaço central no debate público e, longe de constituir um fenômeno restrito às periferias das grandes cidades, inscreve-se na dinâmica das próprias instituições do Estado, sobremodo no aparato policial² ${ }^{2}$ As práticas arbitrárias, ilegais e violentas empregadas pelas forças de segurança do Estado são comumente aceitas pelas instituições jurídicas e compõem, ao lado da corrupção e extorsão, as principais formas de gestão da delinquência nas cidades. 0 fenômeno do Esquadrão da Morte, em São Paulo, ritualizado por policiais civis entre 1968 e 1971, é um exemplo emblemático dessas práticas ilegais, que agindo a serviço de interesses privados acabava por defender e fortalecer a economia do crime.

Uma parcela significativa das execuções sumárias perpetradas pelo Esquadrão da Morte tinha por finalidade a proteção de quadrilhas envolvidas no tráfico de entorpecentes: membros da Polícia Civil eliminavam concorrentes de alguns chefes do tráfico em troca da participação nos lucros das atividades ilegais. Essa ação homicida, entretanto, transbordava para a sociedade através de uma representação heroica do policial, como o indivíduo que agia sozinho para fazer justiça com as próprias mãos (MANSO, 2012). Toleradas pelo poder público, pelos órgãos de imprensa e pela sociedade civil, as ações do Esquadrão da Morte inauguraram uma nova forma de gerir os ilegalismos na cidade de São Paulo, e contribuíram para expandir o fenômeno da violência urbana.

O desmantelamento do Esquadrão da Morte em 1971 deixou um espaço vazio, que foi ocupado posteriormente por outro ator homicida, os justiceiros, no início da década de 1980. A emergência desse grupo teria sido uma resposta dos morado-

1 Graduandos em Ciências Sociais - USP

2 Os autores agradecem ao prof. Laurindo Dias Minhoto pela orientação e à colega Fernanda Emy Matsuda pelas inúmeras contribuições. 
da década de 1980. A emergência desse grupo teria sido uma resposta dos moradores das periferias a criminosos locais, num cenário de ausência do estado e violência urbana crescente. Os justiceiros formavam milícias que funcionavam como uma espécie de segurança privada, num sistema em que os principais beneficiados eram comerciantes e industriais dos bairros de periferia, e que remuneravam esses atores em troca da higienização do território (MANSO, 2012).

A atuação dos justiceiros nas periferias de São Paulo deu origem a um ciclo interminável de execuções: o poder conquistado por esses sujeitos, associado ao medo e ao desejo de vingança por parte de amigos e familiares das vítimas desse sistema, fez com que os próprios justiceiros se tornassem alvo de criminosos. Manso (2012) evidencia o homicídio como turn point dos sujeitos, ou seja, uma vez tendo ingressado nesse tipo de crime, o indivíduo se insere num ciclo de vingança ininterrupto, tendo à sua frente duas escolhas: continuar matando ou ser assassinado.

Subsequentemente, ocorre em São Paulo a consolidação do comércio varejista de drogas nos anos 1990, e sua disputa por mercados e territórios (TEIXEIRA, 2012; MANSO, 2012). Nessa época, os justiceiros começam a dividir o espaço com traficantes e grupos de extermínio policiais, situação que contribuiu para elevar substancialmente a taxa de homicídios na capital paulista. A disputa pelo controle de territórios e do tráfico de drogas, as execuções sumárias praticadas por policiais e justiceiros, e os ciclos de vingança ritualizados nas periferias contribuíram para que a cidade de São Paulo alcançasse taxas exorbitantes de homicídios na década de 1990. Exemplo disso foi a classificação do Jardim Ângela - distrito na zona sul da capital paulista - como a região mais violenta do mundo em 1996, com 116 homicídios por 100 mil habitantes (ONU, 1996).

A incapacidade do estado em conter uma escalada do crime em fins dos anos 1980 fortaleceu o argumento que a única forma de conter a criminalidade seria insistir no modus operandi das forças policiais. Conforme relato do deputado Erasmo Dias (apud TEIXEIRA, 2012, p. 102):

[...] está havendo uma "psicose de direitos humanos, sem que ninguém se preocupe com direitos das vítimas". Após defender o ponto de vista de que a violência às vezes é necessária, observou que é necessário não confundir violência com violência policial, porque aquela reflete a violência da própria sociedade. Erasmo Dias disse ainda, que "tem pena de São Paulo com este negócio de se exigir mandado para colocar bandido na cadeia" (O Estado de São Paulo, 13/09/1979, p. 21).

Essa dinâmica arbitrária e violenta das instituições e agentes do estado ameaçam a própria qualidade da democracia, ao questionar uma prerrogativa básica da cidadania: o direito à vida. A redemocratização do país e a promulgação de uma nova Constituição formalizou uma série de direitos civis e sociais, mas a universalização 
desses direitos ainda não foi efetivada, de modo que os mais pobres continuam sendo submetidos a práticas arbitrárias e violentas do aparelho policial, em condições similares às observadas durante o regime autoritário (NEVES, 2012).

Na virada do século, a taxa de homicídios da capital paulista iniciou um movimento de queda acentuada, reduzindo 74\% entre 2001 e 2010 (BRASIL, 2015a). Entre as principais hipóteses para explicar o fenômeno, destaca-se a atuação de uma facção criminosa nas prisões e no espaço urbano - em especial nas periferias - denominada Primeiro Comando da Capital (PCC); que assumiria a prerrogativa de gerir a violência nos territórios sob seu controle, interrompendo os ciclos de vingança homicidas. Entretanto, a influência de outros fatores, tais como a política pública do desarmamento, a política de encarceramento em massa e as inovações na política de segurança pública, questionariam a hipótese de que o PCC seria o único responsável pela redução dos homicídios em São Paulo (DIAS, 2011; FELTRAN, 2010a; MANSO, 2012).

Nesses termos, o objetivo deste artigo é analisar: (1) a emergência e consolidação do PCC nas prisões e periferias; (2) de que forma essa facção criminosa atua na gestão da violência em São Paulo; e (3) se a atuação do PCC na gestão da violência pode ser considerada um dos principais fatores para a queda da taxa de homicídios em São Paulo.

A política de encarceramento em massa - em vigor no estado de São Paulo desde meados dos anos 1990 - pode ter contribuído para reduzir o número de mortes violentas na capital, mas parece constituir um paradoxo da política de segurança pública: ao recolher criminosos avulsos das ruas e os colocar em contato com facções dentro dos presídios, ela acaba fortalecendo a criminalidade organizada.

\section{PCC: origem, configuração e consolidação da facção criminosa}

A origem do PCC é objeto de inúmeras controvérsias e várias hipóteses já foram levantadas para explicar a fundação do grupo. A principal delas relaciona o nascimento da facção criminosa a um jogo de futebol realizado na Casa de Custódia e Tratamento de Taubaté, envolvendo dois grupos: o Comando Caipira e o Primeiro Comando da Capital (PCC). A partida resultou na morte de dois integrantes do Comando Caipira e, para se protegerem do castigo dos funcionários da instituição, os integrantes do PCC teriam firmado um pacto de proteção mútua (BIONDI, 2007).

Esse evento suscitou, por parte dos fundadores do PCC, a redação de um estatuto que visava organizar os presos contra os maus-tratos sofridos no sistema penitenciário. 0 documento também pretendia regular a conduta dos presos para que a opressão não partisse deles próprios (BIONDI, 2007). 0 lema da facção (Paz, Justiça 
e Liberdade) veio expressar os ideais dos seus integrantes: paz nas prisões através da regulação dos conflitos, levando à redução da violência; justiça para os presos, que passam a reivindicar do estado o respeito aos direitos humanos, de modo a pôr fim aos maus tratos, à superlotação das celas e às falhas no sistema de execução penal; e a liberdade, que passa a ser facilitada por um sistema que exige dos membros da facção (os irmãos) o pagamento de uma contribuição periódica, destinada à cobertura das despesas legais dos presos.

Biondi (2007, p. 208) afirma que "a criação do PCC é vista por muitos presos como o fim de um tempo no qual imperava algo que se aproximava de um cenário 'hobbesiano' de guerra de todos contra todos". Nessa mesma linha, Feltran (2012, p. 136) argumenta que o surgimento do PCC em 1993 teria sido "uma resposta da população carcerária ao Massacre do Carandiru", ocorrido no ano anterior, quando policiais militares invadiram o Pavilhão 9 da Casa de Detenção para controlar uma rebelião, em ação que resultou na morte de cento e onze presos.

Em seus primeiros anos de atuação o PCC lutou para firmar-se como facção hegemônica no estado de São Paulo, promovendo rebeliões e massacres em unidades prisionais na tentativa de eliminar facções rivais. Esse cenário de guerra alcançou um ponto culminante em 2001, quando o PCC coordenou uma mega rebelião em 26 presídios do estado, fato que veio a ser um divisor de águas por duas razões: (1) pela primeira vez ficou evidente para o estado e para a sociedade civil que havia uma facção criminosa capaz de coordenar rebeliões simultâneas em vários presídios paulistas, com vistas à conquista de objetivos comuns; e (2) a partir desse evento o ideal de igualdade $^{3}$ foi incorporado ao lema do PCC (FELTRAN, 2012).

Segundo Biondi (2007), o PCC não assume uma estrutura hierárquica e piramidal mas está organizado em rede por associações diversas. Nessa lógica em que a igualdade ocupa um valor central, qualquer imposição ou obrigação é interpretada como expressão de desigualdade e desrespeito. A disciplina do PCC, pelo contrário, dilui a individualidade dos seus membros aos ideais do Comando, fazendo com que eles atuem em sintonia e correndo pelo certo. Por essa razão as decisões são sempre consensuais, e nas questões mais graves, membros prestigiados da facção (as torres) participam das deliberações (BIONDI, 2007).

Esse processo de desindividualização dos membros do PCC dificulta a identificação de lideranças da facção criminosa, fato que poderia contribuir para a adoção de medidas de desarticulação da criminalidade organizada. Ademais, parte do prestígio e da legitimidade do PCC decorre do fato que seus membros, e a população

3 Esse ideal expressa o discurso de descentralização e horizontalização das relações de poder no âmbito da facção. O PCC, contudo, possui uma cúpula composta por irmãos com elevado prestígio (as torres) que detêm certas prerrogativas de decisão. Em termos gerais, portanto, a igualdade não impede a existência de uma hierarquia (DIAS, 2011). 
carcerária em geral, entendem que as relações entre si são pautadas pela igualdade (FELTRAN, 2010a).

0 ingresso de um detento no PCC geralmente ocorre em duas etapas. Num primeiro momento, um indivíduo inserido no convívio de um presídio comandado pela facção criminosa passa a ser considerado um membro da família ou primo. Dependendo da sua conduta, ou seja, do seu proceder, ele pode ser convidado por membros do Comando a ingressar no PCC como irmão. Para que isso aconteça é preciso que ele tenha a indicação de no mínimo dois irmãos, que serão seus padrinhos de batismo e responsáveis pelas suas ações futuras na facção. Com o batismo, o primo é alçado ao status de irmão ${ }^{4}$ (BIONDI, 2007).

O controle do PCC sobre um território independe da presença de irmãos no local: se num presídio não houver um membro batizado da facção, ele pode ser comandado por membros da família, os primos. Estes, por sua vez, atuam como representantes dos irmãos até a chegada de algum deles ao local, o que geralmente ocorre pelo ingresso de novos detentos ou pela transferência de presos vindos de outras unidades (BIONDI, 2007).

Inicialmente circunscrito às unidades prisionais, em pouco tempo o PCC foi capaz de estender seu domínio às periferias de São Paulo. No início dos anos 2000, a facção criminosa começava a assumir o controle de algumas atividades ilegais nesses territórios, embora seu papel fosse mais de regulador ${ }^{5}$ do que administrador da economia criminal (DIAS, 2011).

\section{Dentro dos muros: o PCC nas prisões}

Nas prisões, a regulação da conduta dos indivíduos pelo PCC teve início logo após a fundação da facção criminosa. Feltran (2012) cita a interdição do estupro e do uso do crack como exemplos emblemáticos da autoridade do Comando. Essas proibições teriam contribuído para reduzir os episódios de violência dentro dos muros, em especial os que resultavam em mortes. Nesse contexto, três figuras são responsáveis nas prisões por garantir a observância dos presos ao padrão de conduta (o proceder), atuando também na mediação dos conflitos: os faxinas, os pilotos e as torres.

Faxinas são os presos encarregados da administração interna do pavilhão, atuando na entrega de comida, abertura e fechamento das celas, resolução de conflitos, entre outros. 0 termo faxina é também uma referência à cela ocupada por esses presos, geralmente irmãos ou primos na iminência do batismo. Tendo em vista que

4 A estimativa é que a proporção de irmãos (membros batizados do PCC) frente à população carcerária de um presídio seja de um irmão para cada cem detentos (BIONDI, 2007).

5 Essa dinâmica permanece a mesma em tempos recentes: o PCC é uma facção criminosa voltada à organização dos presos e à regulação da conduta de criminosos e dos moradores das periferias. Seu foco não é a administração da economia criminal mas sua regulação, e essa é uma diferença fundamental entre o PCC e outras organizações criminosas (DIAS, 2011). 
o PCC proíbe o contato direto dos presos com os funcionários - atitude interpretada como cooperação com o inimigo - os faxinas constituem o elo entre esses dois grupos para efeito de comunicação (BIONDI, 2007).

A figura do piloto pode assumir duas variantes: o piloto de pavilhão e o piloto da cadeia. 0 piloto de pavilhão é o responsável pelo funcionamento do pavilhão: ele representa os presos perante a administração da prisão e assume a responsabilidade pelas suas ações. Ele também garante o cumprimento da bandeira branca, que é a proibição dos presos de iniciarem ou conduzirem qualquer motim, levante ou rebelião. Esses eventos, quando ocorrem, são de iniciativa das torres e coordenadas por elas em parceria com os pilotos (BIONDI, 2007).

O piloto da cadeia, por sua vez, é quem discute e negocia com a administração da prisão acerca dos problemas que afetam os presos, tais como transferências e melhoria das condições prisionais. Biondi (2007, p. 224) afirma que "essas negociações costumam ter como objetivo garantir aos presos o que eles chamam de um 'cumprimento digno de sua pena', mas também garantir à instituição a ordem e o controle da população carcerária". 0 piloto da cadeia é também o elo da população carcerária com as torres, que são os "presos prestigiados, reconhecidos, considerados no PCC. É delas que, idealmente, partem as diretrizes, comunicados e recomendações do Partido para todas as suas unidades, os chamados salves" (BIONDI, 2007, p. 226).

O piloto é um irmão, e como tal, sua atuação deve ser pautada pelo respeito aos valores do PCC (Paz, Justiça, Liberdade e Igualdade). Se ele incorre em abuso de autoridade, sua legitimidade passa a ser questionada pelos demais presos, o que reduz sua capacidade de negociação e pode levar a insurgências. Nesses casos, o piloto é removido do seu posto por alguma torre e pode ser punido pelo seu desvio de conduta. É para evitar atitudes isoladas e abuso de autoridade que várias prisões têm mais de um piloto: em alguns casos ao menos três presos dividem essa função, e isso vale tanto para o piloto de pavilhão quanto para o piloto da cadeia. Essa dinâmica expressa a impossibilidade, para um piloto, de assumir uma posição de liderança, afinal "a responsabilidade atribuída (por presos batizados ou não) aos irmãos não é de governar a prisão, mas de ali instaurar e fazer cumprir os ideais do Comando" (BIONDI, 2007, p. 229).

Em relação às torres ${ }^{6}$, nem mesmo os demais presos sabem quem elas são. Apenas os pilotos mantêm contato com elas, e eles são proibidos de divulgar sua identidade, pois isso poderia levar ao seu isolamento através do Regime Disciplinar

6 A atuação das torres seria como uma espécie de poder foucaultiano que circula nos interstícios do tecido social, guiando a conduta dos indivíduos por meio de um governo de si (FOUCAULT, 2010). 
Diferenciado ${ }^{7}$ (RDD). Biondi (2007, p. 229) afirma que "tudo se passa como se uma força desconhecida e superior fosse responsável pelo modo de operação ou de exercício dos poderes que circulam nas prisões".

\section{Fora dos muros: o PCC nas periferias de São Paulo}

Feltran (2010a) argumenta que até o início dos anos 1980 o crescimento econômico do país tinha sido capaz de fomentar um projeto familiar de ascensão social e conquista de bem-estar. Esse equilíbrio entre projeto nacional e projeto familiar teria contribuído para manter a coesão social num cenário de urbanização caótica e infraestrutura urbana precária, em especial nas periferias das cidades.

Nos anos 1990 houve um esfacelamento desse equilíbrio, num contexto de estagnação econômica e desemprego persistente. A instituição familiar enfrentava uma profunda crise, reflexo da desregulamentação, terceirização, enxugamento e precarização do trabalho. Nesse cenário de hegemonia das políticas neoliberais, a consolidação do tráfico de drogas favoreceu a cooptação das massas desprezadas por um mercado de trabalho cada vez mais exigente. Feltran (2010a) destaca que até os anos 1980 a população das periferias de São Paulo operava numa chave de duas representações opostas: o trabalhador e o bandido. Já na década seguinte, a fronteira entre essas duas representações diluiu-se: o crime deixou de ser visto como o inimigo e passou a ser uma forma de vida possível, e também uma fonte de renda.

Feltran (2010a) destaca a sincronia de dois movimentos, em princípio, opostos: a consolidação do regime democrático e a ascensão do PCC. Foi nesse cenário que a facção criminosa começou a assumir, nas prisões e posteriormente nas periferias da capital paulista, uma função tipicamente estatal: a administração da justiça. E foi num contexto de maior fragmentação e precarização da rede de proteção social que

A política de encarceramento em massa em São Paulo quase quadruplicou a população carcerária do Estado, [retirando] uma parcela significativa dos criminosos das vielas de favela para inseri-los em redes bastante mais conectadas do mundo criminal, que operam, sobretudo, nos presídios. 0 período de encarceramento massivo corresponde, exatamente, ao período de expansão e ampliação do poder do PCC (FELTRAN, 2010a, p. 69).

A partir de 2001 o PCC emerge nas periferias de São Paulo como expressão da consolidação do seu poder político-jurídico na esfera prisional paulista. Essa expansão foi resultado da libertação gradual de irmãos que estavam presos e que, após um tempo cumprindo pena nos presídios, acabam retornando às suas comunidades de origem nas periferias e ali instituem o Comando (FELTRAN, 2012).

7 Modalidade de execução penal caracterizada pelo isolamento total do preso por até um ano, período no qual ele tem seu direito de visita restringido, permanecendo confinado vinte e duas horas por dia numa cela individual e saindo por duas horas diárias para tomar banho de sol (ADORNO; SALLA, 2007). 
Entre os principais fatores explicativos da legitimidade que a facção passa a assumir nas periferias, Feltran (2010a) destaca a morosidade e as injustiças da burocracia estatal. A esse respeito, o argumento de Neves (2012) é que atores políticos e econômicos promovem uma instrumentalização do aparelho burocrático-legal do estado que compromete a universalização dos direitos de cidadania. 0 resultado desse processo é o surgimento de duas categorias de cidadãos: abaixo do direito estariam os subintegrados, e acima dele os sobreintegrados.

Na condição de subintegração os sujeitos têm acesso precário ao aparelho burocrático-legal, o que compromete a garantia e o exercício dos seus direitos de cidadania. Entretanto, esses indivíduos não se encontram totalmente excluídos, pois o estado continua a exigir deles o cumprimento de deveres e responsabilidades. Em outras palavras, a condição de subintegração aproxima-se do que Wacquant (2001) define como criminalização da pobreza. Inversamente, os cidadãos sobreintegrados são indivíduos privilegiados "titulares de direitos, competências, poderes e prerrogativas" (NEVES, 2012, p. 250) que desenvolvem ações bloqueantes da reprodução do direito. Nessa condição, o aparelho burocrático-legal é empregado para a consolidação de interesses privados, representados por sujeitos de direito desobrigados de cumprir certos deveres e responsabilidades.

Essa estrutura de cidadania hierarquizada teria favorecido a consolidação do PCC enquanto poder político-jurídico nas periferias da capital paulista. Isso porque a facção criminosa estabeleceu um sistema de regulação normativa que exerce sua autoridade não apenas sobre a conduta de criminosos, mas também sobre os cidadãos subintegrados que residem nas periferias de São Paulo, e que recorrem ao PCC em busca de algum tipo de justiça. E o dispositivo criado pela facção criminosa para resolver litígios e punir os desvios de conduta são os debates ou tribunais do crime.

Um debate descrito por Feltran (2010a) ilustra a extensão do mecanismo de regulação normativa do PCC. 0 autor cita o exemplo de um morador da periferia de São Paulo que, ao descobrir a infidelidade da esposa, havia jurado matá-la. 0 conflito foi mediado pelo gerente da biqueira ${ }^{8}$, que após deliberação resolveu dar ao homem duas alternativas: ele podia colocar a esposa pra fora de casa ou dar uma surra nela; mas não foi dada autorização ao homem para matar sua esposa.

Os debates operam como parte de um sistema regulado de resolução de conflitos. Sua diferença básica em relação ao aparato de justiça estatal é que ele constitui, por definição, um tribunal de exceção. Sua pena máxima é a morte e outras formas de violência física, tais como surras, são comuns. Não existe garantia de direito à vida, apenas o respeito aos princípios da facção, como justiça e igualdade (FELTRAN, 2010a).

8 Ponto de venda de drogas (FELTRAN, 2010a). 
Nesses debates o réu tem direito à defesa, podendo apresentar sua versão dos fatos e convocar testemunhas para defendê-lo, e a acusação também é livre para se manifestar, apresentando provas e argumentos. Nas periferias, a comunidade local tem autonomia para realizar os debates, que geralmente são conduzidos pelo proprietário da biqueira ou por seu gerente. Além disso, nos debates em que a pena de morte é passível de aplicação, quando estão sendo julgados desvios graves do proceder, a presença ou participação à distância de uma torre é obrigatória: a sentença de pena de morte somente pode ser autorizada com o seu aval (FELTRAN, 2010a).

Feltran (2010a) argumenta que o debate cumpre ao menos três funções: (1) reafirma a autoridade da facção em punir desvios de conduta; (2) evidencia a justiça do procedimento e legitima a autoridade dos juízes; e (3) interrompe o ciclo de vinganças privadas que se seguiriam caso o conflito não fosse resolvido a tempo, ou se alguém decidisse fazer justiça por conta própria, sem a autorização do PCC. Hirata (2010) observa que um debate pode ter dois desfechos possíveis: a morte regulada, para os casos em que o desvio do proceder é grave e imperdoável; ou um pacto que é firmado entre o réu e a vítima para desativar o dispositivo de vingança privada. Nesse último caso, muitas vezes o pacto é viabilizado pela intervenção de um irmão que se torna fiador do réu, ou seja, responsável por suas ações futuras: manter o compromisso de não se vingar e tampouco repetir o desvio de conduta.

A legitimidade do PCC nas periferias de São Paulo decorre da percepção, por parte da população desses bairros, de que a justiça estatal, além de ineficiente, é profundamente desigual (FELTRAN, 2010a). Ela é a grande responsável pelo encarceramento em massa dos seus habitantes, geralmente tratados pela polícia com uma mistura de indiferença e desrespeito. 0 próprio estado marginaliza e criminaliza os moradores das periferias, e há décadas tem dado as costas para tudo de ilegal que acontece nesses territórios. Em contrapartida, a justiça promovida pelos debates do PCC é percebida como universalista e igualitária, uma vez que o respeito ao proceder é exigido de todos os indivíduos, num sentido realmente democrático. Apenas delatores, estupradores e pedófilos são julgados de modo distinto pela facção, pois suas ações remetem a desvios considerados imperdoáveis no mundo do crime.

Segundo Feltran (2010b), nas periferias de São Paulo o sistema de justiça estatal divide espaço com outros aparatos normativos que servem de referência para os moradores desses territórios. Os principais deles são a justiça do PCC e a justiça da polícia.

A justiça do PCC, enquanto aparato normativo gerido pela facção criminosa, exige de criminosos e moradores das periferias a observância a um padrão de conduta (o proceder). Esse sistema adota como princípios básicos a não cooperação com a 
polícia e a gestão da violência nos territórios comandados pelo PCC (FELTRAN, 2010b).

A justiça da polícia é um aparato normativo tipicamente aplicado por policiais do baixo escalão. Esse sistema reflete a situação ambígua enfrentada pelos policiais que atuam nas periferias de São Paulo: por um lado eles têm o dever de cumprir as leis do estado, e por outro, tem que operar diretamente com a lógica de ação do PCC. Nesse cenário, as ações policiais ocorrem em zonas que vão da estrita legalidade à total ilegalidade, passando por muitas matizes. As relações entre a polícia e o PCC são assim descritas por Feltran:

\begin{abstract}
Assim, um modo específico de gestão do uso da violência nas interações entre a polícia e o crime é estabelecido. Não existe agressão física, tampouco troca de tiros ou enfrentamento, mas um conflito 'contido' inserido numa esfera de interação discursiva voltada ao alcance de acordos financeiros (FELTRAN, 2010b, p. 122, tradução nossa)
\end{abstract}

Essa dinâmica de relações assemelha-se ao que Foucault denominou de gestão diferencial dos ilegalismos, definido pelo autor como

práticas ilegais sobre o qual se chega a exercer o controle e tirar um lucro ilícito por meio de elementos ilegais, mas tornados manejáveis por sua organização em delinquência. Este é um instrumento para gerir e explorar ilegalidades. [Por sua vez] a delinquência, ilegalidade dominada, é um agente para a ilegalidade dos grupos dominantes (FOUCAULT, 2010, p. 264-265).

No Brasil, o próprio histórico de formação das instituições penais e de segurança pública possui um forte viés de privatização da justiça e controle social baseado na violência, sem que haja a inserção dos infratores no sistema judiciário estatal. Assim, o combate ao crime amparado nas leis e instituições do estado jamais teria sido aplicado de forma plena. Ao contrário, as ações da polícia nas periferias de São Paulo parecem enquadrar-se na gestão diferencial dos ilegalismos, pois a lógica que orienta as relações entre a polícia e o PCC é capaz de gerar resultados diversos e contraditórios: um criminoso que pertença à facção pode ser preso para que a polícia mostre serviço e atinja suas metas de trabalho; suas atividades criminais podem ser toleradas quando existe um acerto com a polícia que garanta a continuidade das atividades; e, frequentemente, a polícia tem a iniciativa de prender unicamente com a função de receber um resgate para que o criminoso não seja fichado e encaminhado à unidade prisional (FELTRAN, 2010b).

As relações entre a polícia e o PCC são marcadamente frágeis, uma vez que dependem da manutenção de um equilíbrio de forças e de um entendimento entre as partes. Um entendimento é expresso por um acordo financeiro extralegal estabelecido entre policiais e criminosos, como forma de evitar prisões e a aplicação da lei. Nessa interação entre a polícia e a facção criminosa, o uso da violência é evitado 
na medida do possível para que a esfera econômica prevaleça sobre o confronto armado, e a negociação sobre os acertos possa ocorrer sem interferências (FELTRAN, 2012).

Dias (2011) argumenta que os ataques ${ }^{9}$ do PCC a agentes públicos, realizados em 2006 na capital paulista, refletem um rompimento desse equilíbrio de forças entre a polícia e a facção criminosa. Situações como essa inauguram uma temporada de acertos de contas entre as partes até que um novo acordo seja feito, e a paz, restaurada. Um dos fatores capazes de explicar os eventos de maio de 2006 seria a iniciativa do estado de isolar lideranças do PCC em presídios com o Regime Disciplinar Diferenciado (RDD). Esse fato teria causado tamanha revolta entre os membros da facção criminosa que as torres ordenaram uma série de ataques a agentes públicos, até que a medida de isolamento fosse revertida.

\section{Fatores intervenientes na redução dos homicídios em São Paulo}

Esta seção tem por finalidade analisar alguns fatores que - segundo acadêmicos - têm intervido sobre a redução dos homicídios em São Paulo em anos recentes (DIAS, 2011; FELTRAN 2012; MANSO, 2012). Serão analisados a seguir: (1) a atuação do PCC na gestão da violência; (2) a política pública do desarmamento; (3) a política de encarceramento em massa; e (4) as inovações na política de segurança pública.

\section{A atuação do PCC na gestão da violência}

Em termos gerais, a gestão da violência pela facção criminosa envolve duas frentes: o mecanismo de regulação normativa exige de criminosos e moradores das periferias a observância a um padrão de conduta (o proceder); e quando ocorre um desvio de conduta, a autoridade punitiva é acionada através dos debates, dispositivos que também são encarregados da resolução de conflitos nos territórios comandados pelo PCC.

Segundo Feltran (2012), a emergência do PCC nas periferias de São Paulo teve início em 2001. Esse momento coincide com um processo gradual de queda dos homicídios perpetrados na cidade: naquele ano a taxa de homicídios era de 57,3 óbitos por 100 mil habitantes, e em 2002 o indicador caiu para 50,3 óbitos/100 mil hab.; um decréscimo de 12,2\%. Em 2003 houve uma leve queda, para 48 óbitos/100 mil hab.; em 2004, um recuo significativo para 37,3 óbitos/100 mil hab.; em 2005, um novo recuo para 26,8 óbitos/100 mil hab. E a tendência de queda prossegue: com exceção de um leve aumento no indicador, em 2009, a taxa de homicídios na capital paulista caiu 73,6\% entre 2001 e 2010, terminando a série histórica com 15,1 óbitos/100 mil

9 Entre maio e agosto de 2006, confrontos armados entre o PCC e a polícia causaram a morte de 564 pessoas no estado de São Paulo (ESTADO DE SÃO PAULO, 2009). 
hab. (BRASIL, 2015a).

Ao comparar a média da taxa de homicídios nos dois períodos, antes e depois da emergência do PCC nas periferias, temos o seguinte resultado: entre 1994 e 2000, a média da taxa de homicídios foi de 56,2 óbitos/100 mil hab.; entre 2001 e 2010, foi de 31,1 óbitos/100 mil hab.; a diferença, portanto, entre as médias das taxas dos dois períodos foi de 44,7\%, e isso pode ser devido à atuação do PCC nas periferias no segundo período. Contudo, nesse período houve também uma queda expressiva dos homicídios em cidades que não testemunharam a emergência de uma facção criminosa como o PCC, tais como Rio de Janeiro (58\%) e Recife (35\%), o que implica em considerar outras explicações para o fenômeno (BRASIL, 2015a).

Ainda sobre o papel do PCC na queda dos homicídios em São Paulo, é preciso destacar outro fator: a existência de um equilíbrio de forças entre a polícia e a facção criminosa (DIAS, 2011). Apesar da sua relativa fragilidade, quando em vigor esse equilíbrio tende a limitar o uso da violência entre as partes, reduzindo o número de mortes decorrentes de confrontos armados entre a polícia e o PCC.

\section{A política pública do desarmamento}

Num estudo realizado em São Paulo em 1995 sobre as causas das mortes em bairros da zona sul, Manso (2012, p. 94) atestou que 56\% dos óbitos decorriam de conflitos interpessoais e 44\% eram resultado da ação de criminosos, sendo $23 \%$ deles oriundos da criminalidade organizada e $21 \%$ da criminalidade não organizada. Portanto, a maioria das mortes não tinha relação com o mundo do crime, mas resultava de conflitos privados.

Nesse cenário, cabe discutir o que poderia ter contribuído para reduzir a letalidade dos conflitos interpessoais em São Paulo na última década. 0 argumento de Manso (2012) é que o Estatuto do Desarmamento de 2003, ao restringir a compra de armas de fogo e tornar o porte crime inafiançável, enquadrou milhões de proprietários ilegais de armas como transgressores da lei. A saída encontrada para muitas dessas pessoas foi aceitar a entrega voluntária de armas e munições através da Campanha do Desarmamento, lançada a partir de 2004. Em São Paulo, a política do desarmamento pode ter contribuído significativamente para a redução dos homicídios ao reduzir a letalidade dos conflitos privados, tirando de circulação armas de fogo que seriam usadas em brigas domésticas, no trânsito ou entre vizinhos. A esse respeito, estudos quantitativos estimam que para cada 18 armas retiradas de circulação houve um homicídio a menos na cidade (CERQUEIRA, 2010 apud MANSO, 2012).

Entretanto, a queda na taxa de homicídios, se por um lado é uma resposta à 
política do desarmamento (MANSO, 2012), também decorre da atuação do PCC na gestão dos conflitos privados (FELTRAN, 2010a). Para os subintegrados que residem nas periferias de São Paulo, os debates, enquanto dispositivo normativo criado pela facção criminosa para resolver litígios e punir os desvios de proceder, contribuiriam de forma expressiva na redução dos ciclos de vingança privados e, consequentemente, dos homicídios decorrentes desses conflitos.

\section{A política de encarceramento em massa}

Em 1994 a taxa de encarceramento no estado de São Paulo era de 260,4 presos por 100 mil habitantes. Em 2001, quando o PCC coordenou uma mega rebelião em 26 presídios paulistas, esse indicador era de 386,7 presos/100 mil hab.. Em 2010, a taxa de encarceramento já havia saltado para 562 presos/100 mil hab..; um incremento de $117 \%$ no período considerado. Esses dados refletem a política de encarceramento em massa promovida pelo estado de São Paulo a partir de meados dos anos 1990. 0 estado que em 1994 somava 55 mil presos em regime fechado iria mais do que triplicar sua população carcerária em apenas dezessete anos, totalizando 170 mil detentos em 2010 (BRASIL, 2014).

A fim de estudar o impacto do encarceramento em massa sobre a queda dos homicídios em São Paulo, o Gráfico 1 apresenta a taxa de encarceramento no estado e a taxa de homicídios na capital paulista no período entre 1994 e 2010. A correlação ${ }^{10}$ entre as duas variáveis é apresentada na Tabela 1, que traz ainda a associação entre a taxa de homicídios e o indicador de demografia ${ }^{11}$. Este indicador, por sua vez, reflete a proporção das pessoas de 15 a 24 anos sobre a população total.

10 Os cálculos foram feitos considerando-se um nível de significância de $5 \%(p<0,05)$.

11 Em virtude da baixa significância estatística do indicador de demografia, optou-se por não discorrer sobre a influência dessa variável sobre os homicídios em São Paulo. 


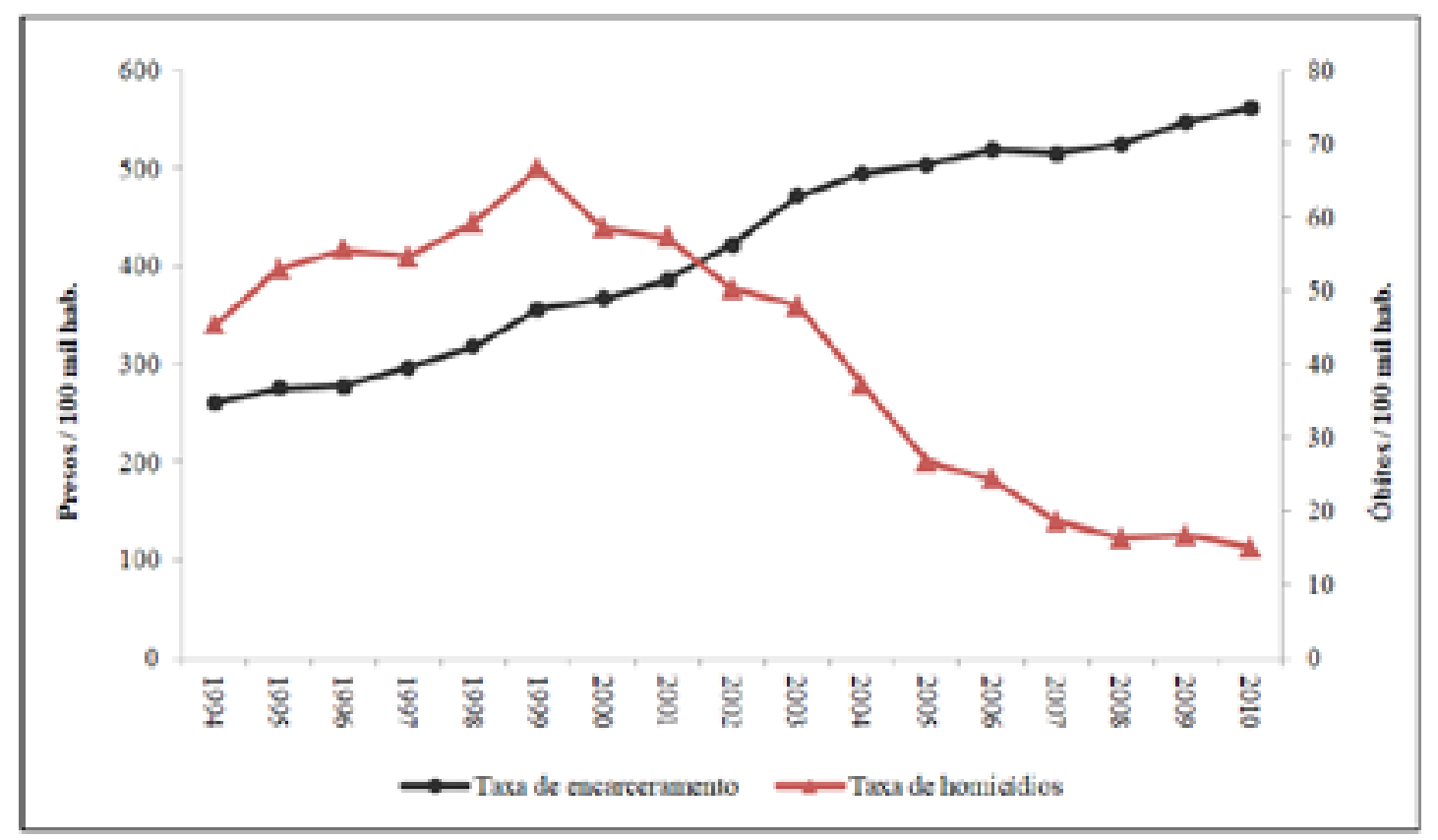

Gráfico 1 - Taxa de encarceramento no estado de São Paulo e taxa de homicídios na capital paulista $(1994-2010)$

Fonte: INFOPEN (2014) e DATASUS (2015a)

\begin{tabular}{|c|c|c|c|c|}
\hline \multirow[t]{2}{*}{ Variáveis } & \multicolumn{4}{|c|}{ Taxa de homicídios (óbitos/100 mil hab.) } \\
\hline & $\mathrm{r}$ & $\mathrm{R}$ & $\alpha$ & $\mathrm{n}$ \\
\hline Taxa de encarceramento & \multirow[t]{2}{*}{$-0,83$} & \multirow[t]{2}{*}{$69 \%$} & \multirow[t]{2}{*}{$<0,01$} & \multirow[t]{2}{*}{17} \\
\hline (presos/100 mil hab.) & & & & \\
\hline Demografia & \multirow[t]{2}{*}{$-0,29$} & \multirow[t]{2}{*}{$8 \%$} & \multirow[t]{2}{*}{0,27} & \multirow[t]{2}{*}{17} \\
\hline (pessoas 15-24 anos/pop. total) & & & & \\
\hline
\end{tabular}

Tabela 1 - Relação entre taxa de homicídios, taxa de encarceramento e demografia em São Paulo (1994 - 2010)

Nota: $r$ representa a correlação, $\mathrm{R}$ a variância, $\alpha$ o nível de significância e $\mathrm{n}$ o tamanho da amostra.

Fonte:Elaboração própria, a partir dos dados de INFOPEN (2014), DATASUS (2015a) e DATASUS (2015b).

Os resultados mostram que a taxa de encarceramento opera numa relação inversa à taxa de homicídios. Em outros termos, a política de encarceramento em massa promovida pelo estado de São Paulo pode ter contribuído para reduzir os homicídios. Nadanovsky (2009) também encontrou resultados semelhantes, argumentando que o encarceramento incapacita e dissuade os indivíduos de cometerem crimes, sobremodo em função da possibilidade de punição sob a forma de restrição de liberdade.

Contudo, é possível questionar essa relação entre encarceramento ehomicídios.Em Minas Gerais, entre 2002 e 2010, ambos os indicadores aumentaram expressiva- 
mente: em 2002, o estado mineiro registrou uma taxa de homicídios de 16,3 óbitos por 100 mil habitantes, ao passo que em 2011 foram 21,5 óbitos/100 mil hab.; no mesmo período a taxa de encarceramento foi de 125/100 mil hab. para 250/100 mil hab.; respectivamente (CRUZ; SOUZA; BATITUCCI, 2013). Portanto, a relação inversa entre as taxas de encarceramento e de homicídios em São Paulo, em vez de expressar uma relação de causalidade, pode resultar apenas de coincidência temporal. Conforme demonstrado por diversos autores (ADORNO \& SALLA, 2007; BIONDI, 2007; DIAS, 2011; MANSO, 2012; FELTRAN, 2012; TEIXEIRA, 2012), o encarceramento em massa tem produzido efeitos nefastos sobre a sociedade e não parece ser o meio mais adequado para enfrentar o problema da violência urbana. A introdução de uma política de encarceramento em massa no estado de São Paulo, inspirada na experiência estadunidense, gerou um recrudescimento penal que reduziu a tolerância a pequenos desvios (CRUZ; SOUZA; BATITUCCI, 2013); favoreceu a emergência de uma cultura do controle e a hipertrofia da mão direita do Leviatã; e levou à marginalização e criminalização da pobreza (GARLAND, 2001).

A esse respeito, um estudo realizado por Cavadino e Dignan (2006) em doze países encontrou uma relação direta entre as políticas econômica e penal adotadas pelos estados. Inicialmente foi realizada a classificação dos regimes econômicos em quatro tipos: neoliberal, corporativista conservador, socialdemocrático e corporativista oriental, e segundo o modelo proposto por Cavadino e Dignan (2006), os estados neoliberais estabelecem a repressão policial e a prisão como principais mecanismos de controle e manutenção da ordem, o que faz com que esses países apresentem as maiores taxas de encarceramento em relação aos demais regimes econômicos; políticas populistas de punição; ethos individualista; e marginalização socioeconômica. Ademais, nos estados neoliberais os trabalhadores tendem a se transformar em commodities, pois na medida em que um indivíduo perde a capacidade de atender às necessidades do mercado, ele passa a ser excluído da própria sociedade. É como se a desordem e a anomia deflagradas pelo livre mercado não pudessem ser ameaçadas por esses marginais.

Em contraste, países que adotam outros regimes econômicos - em especial de inspiração socialdemocrática - apresentam taxas reduzidas de encarceramento devido a fatores como: universalização de direitos; promoção de políticas de bem-estar social pelo estado; e maior sensibilização dos cidadãos para o cumprimento de obrigações coletivas, fortalecendo laços de pertencimento e solidariedade (CAVADINO; DIGNAN, 2006).

De acordo com o modelo de Cavadino e Dignan (2006), países como o Brasil adotam um regime econômico neoliberal ao estabelecer uma dependência entre o 
se ajustarem a essa lógica. É nesse contexto que a instituição familiar é afetada por fatores econômicos e sociais, o que favorece novas dinâmicas dos atores envolvidos no mundo do crime e fronteiras mais permeáveis entre trabalhadores e bandidos.

Assim, determinados valores sociais seriam subvertidos para a obtenção de sucesso econômico e poder de consumo. 0 endurecimento da política penal em São Paulo pode ter contribuído para a queda dos homicídios ao promover o encarceramento em massa da população, mas isso também favoreceu a organização e consolidação da criminalidade organizada dentro dos presídios. Por outro lado, o sistema jurídico-penal precariza os direitos dos cidadãos que cometem transgressões, o que aprofunda a exclusão social e reduz suas possibilidades de recuperação e reintegração à sociedade. Em outros termos, o estado agrava a situação do transgressor e o condena à dependência da economia criminal.

Dessa forma, o paradoxo da política de segurança pública parece residir justamente na política de encarceramento em massa. Se por um lado ela reduz o número de mortes violentas ao retirar de circulação um contingente expressivo de criminosos; por outro, acaba fortalecendo a criminalidade organizada ao recolher criminosos avulsos das ruas e os colocar em contato com facções dentro dos presídios (TEIXEIRA, 2012). Esse processo leva ao emprego de maior violência pelo aparato policial e pode conduzir à violação crescente dos direitos humanos, medidas muitas vezes justificadas como necessárias no combate à criminalidade organizada (WACQUANT, 2003). Além disso, o avanço do estado penal tem sido acompanhado por: atrofia das políticas sociais; normatização e criminalização da conduta dos mais pobres; políticas de segurança repressiva; clivagens e militarização de áreas urbanas; divisão de territórios e restrição da mobilidade dos cidadãos (WACQUANT, 2003; WACQUANT, 2010; CALDEIRA, 2002; GRAHAM, 2011).

\section{As inovações na política de segurança pública}

Manso (2012) argumenta que as inovações adotadas pelo governo do estado de São Paulo na política de segurança pública, a partir de meados dos anos 1990, contribuíram de forma significativa para a redução dos homicídios em São Paulo. Inspiradas na experiência estadunidense de redução da criminalidade através da combinação de vigilância, tecnologia e patrulhamento estratégico, essas medidas incluíram: a criação, em 1999, do Registro Digital de Ocorrências (RDO), que informatizou o registro das ocorrências policiais, e do Sistema de Informações Criminais (Infocrim), que faz o cruzamento dos boletins de ocorrência e gera um mapa do crime que orienta as ações policiais, estabelecendo os hotspots (SÃO PAULO, 2010).

Outras medidas importantes foram a reorganização do trabalho policial, com 
a adoção de indicadores de produtividade, tais como a adoção de cotas para abordagem policial; a elevação das prisões em flagrante, em especial por porte ilegal de arma; a queda no número de fugas prisionais; e a redução drástica das carceragens existentes em delegacias da capital paulista (MANSO, 2012).

\section{Considerações finais}

Esse artigo teve por objetivo explorar qual a contribuição do estado para a emergência e consolidação do PCC, e de que forma essa facção criminosa atua na gestão da violência em São Paulo, influindo na queda da taxa de homicídios da capital paulista.

A partir do que foi exposto, é possível validar a tese que o PCC, ao promover a gestão da violência nas periferias, contribuiu para reduzir a taxa de homicídios na capital paulista. Esse processo se deu pelo emprego, por parte do PCC, de dois instrumentos de gestão da violência: um mecanismo de regulação de condutas (o proceder) e um dispositivo jurídico encarregado de punir os desvios e regular os conflitos (os debates ou tribunais do crime).

Em termos gerais, o PCC exerce o controle e a regulação sobre o uso da violência nos territórios comandados pela facção, e quando se trata da violência extrema (morte), esse poder chega ao nível de monopólio. Nas prisões e periferias de São Paulo, matar um indivíduo é algo que depende de autorização do PCC, que somente pode ser concedida num debate, em que são julgados o proceder do réu e da vítima.

A atuação do PCC também contribui de forma indireta na redução dos homicídios ao induzir a polícia a estabelecer determinadas relações com a facção criminosa. Essas, por sua vez, são marcadas pela gestão diferencial dos ilegalismos, contribuindo para a manutenção de um equilíbrio de forças entre a polícia e o PCC, em que há um predomínio da negociação financeira sobre o uso da violência. Exceto nos episódios de rompimento desse equilíbrio, a tendência tem sido de episódios raros de confrontos armados esporádicos entre as partes, o que tem contribuído para reduzir o número de homicídios de policiais e criminosos na capital paulista.

0 presente trabalho, contudo, não pretende limitar a explicação da queda da taxa de homicídios em São Paulo à atuação do PCC na gestão da violência, tendo em vista que outros fatores parecem exercer influência sobre o fenômeno. A esse respeito, constatou-se que a política pública do desarmamento tirou de circulação milhares de armas que poderiam ter sido usadas em conflitos privados. Similarmente, a política de encarceramento em massa e o recrudescimento do estado penal contribuíram para reduzir o número de mortes violentas em São Paulo. No entanto, o paradoxo é evidente, pois se em parte houve sucesso na redução dos homicídios, a 
criminalidade organizada se viu fortalecida na medida em que criminosos avulsos foram inseridos numa rede organizada e pulverizada por todo o território paulista. Em relação às inovações na política de segurança pública, parece provável que essas medidas tenham um impacto positivo sobre a redução da taxa de homicídios em São Paulo, em virtude do maior enfoque da polícia em vigilância, recursos tecnológicos e reorganização do trabalho policial.

\section{Referências bibliográficas}

ADORNO, Sérgio; SALLA, Fernando. Criminalidade organizada nas prisões e os ataques do PCC. Estudos Avançados (USP), São Paulo, v. 21, no 61, 2007, p. 7-29.

BIONDI, Karina. Relações políticas e termos criminosos: o PCC e uma teoria do irmão-rede. Teoria \& Sociedade (UFMG), Belo Horizonte, v. 15, nํ 2, 2007, p. 206-235.

BRASIL. Ministério da Justiça. INFOPEN. Apresenta os dados de população carcerária. 2014. Disponível em: < http://www.infopen.gov.br/> Acesso em: 13 jun. 2014.

BRASIL. Ministério da Saúde. DATASUS. Indicadores de mortalidade: apresenta a taxa de mortalidade específica por causas externas. 2015a. Disponível em: <http:// tabnet.datasus.gov.br/cgi/deftohtm.exe?idb2011/c09.def> Acesso em: 18 mar. 2015.

BRASIL. Ministério da Saúde. DATASUS. Informações de saúde: apresenta a população residente segundo faixa etária, sexo e situação de domicílio. 2015b. Disponível em: <http://tabnet.datasus.gov.br/cgi/deftohtm.exe?ibge/cnv/popsp.def> Acesso em: 19 mar. 2015.

CAVADINO, Michael; DIGNAN, James. Penal policy and political economy. Criminology \& Criminal Justice, vol. 6, no 4, 2006, p. 435-456.

CERQUEIRA, Daniel Ricardo de Castro. Causas e consequências do crime no Brasil. Rio de Janeiro: PUC-Rio, 2010, 200p.. Tese de Doutorado - Programa de Pós-Graduação em Economia, PUC-Rio.

CRUZ, Marcos Vinicius Gonçalves da; SOUZA, Letícia Godinho de; BATITUCCI, Eduardo Cerqueira. Percurso recente da política penitenciária no Brasil: o caso de São Paulo 
Revista de Administração Pública, v. 47, n. 5, 2013, p. 1307-1325.

DIAS, Camila Caldeira Nunes. Da pulverização ao monopólio da violência: expansão e consolidação do Primeiro Comando da Capital (PCC) no sistema carcerário paulista. São Paulo: USP, 2011, 386p.. Tese de Doutorado - Programa de Pós-Graduação em Sociologia, FFLCH/USP.

ESTADO DE SÃO PAULO. Dos 564 mortos durante os ataques do PCC em maio de 2006, 505 eram civis. 2009. Disponível em: <http://brasil.estadao.com.br/noticias/ geral,dos-564-mortos-durante-os-ataques-do-pcc-em-maio-de-2006-505-eram-civis,393894>. Acesso em: 17 mar. 2015.

FELTRAN, Gabriel de Santis. Crime e castigo na cidade: os repertórios da justiça e a questão do homicídio nas periferias de São Paulo. Caderno CRH (UFBA), Salvador, v. 23, no 58, 2010a, p. 59-73.

.The management of violence on the São Paulo periphery: the repertoire of normative apparatus in the PCC era. Vibrant, Florianópolis, v. 7, no 2, 2010b, p. 109134.

Governo que produz crime, crime que produz governo: o dispositivo de gestão do homicídio em São Paulo (1992-2011). Revista Brasileira de Segurança Pública, São Paulo, v. 6, no 2, 2012, p. 232-255.

FOUCAULT, Michel. Vigiar e punir: nascimento da prisão. Rio de Janeiro: Editora Vozes, 2010.

GARLAND, David. The culture of control: crime and social order in contemporary society. Chicago: University of Chicago Press, 2001.

GRAHAM, Stephen. Cities under siege: The new military urbanism. New York: Verso, 2011.

HIRATA, Daniel Veloso. Sobreviver na adversidade: entre o mercado e a vida. São Paulo: USP, 2010, 367p.. Tese de Doutorado - Programa de Pós-Graduação em Sociologia, FFLCH/USP. 
MANSO, Bruno Paes. Crescimento e queda dos homicídios em SP entre 1960 e 2010: uma análise dos mecanismos da escolha homicida e das carreiras no crime. São Paulo: USP, 2012, 295p. Tese de Doutorado - Programa de Pós-Graduação em Ciência Política, FFLCH/USP.

NADANOVSKY, Paulo. 0 aumento no encarceramento e a redução nos homicídios em São Paulo, Brasil, entre 1996 e 2005. Caderno de Saúde Pública, Rio de Janeiro, v. 25, n. 8, 2009, p. 1859-1864.

NEVES, Marcelo. Entre Têmis e Leviatã: uma relação difícil. São Paulo: Martins Fontes, 2012.

SÃO PAULO (Estado). Secretaria de Estado da Segurança Pública. Sistemas de inteligência criam o mapa da criminalidade. 2010. Disponível em: <http://www.ssp.sp.gov. br/acoes/acoes_sistemas.aspx>. Acesso em 8 mar. 2015.

TEIXEIRA, Alessandra. Construir a delinquência, articular a criminalidade: um estudo sobre a gestão dos ilegalismos na cidade de São Paulo. São Paulo: USP, 2012, 352p.. Tese de Doutorado - Programa de Pós-Graduação em Sociologia, FFLCH/USP.

WACQUANT, Loïc. As prisões da miséria. Rio de Janeiro: Jorge Zahar Editor, 2001.

Punir os pobres: a nova gestão da miséria nos Estados Unidos. Rio de Janeiro: Revan, 2003.

. Crafting the neoliberal state: workfare, prisonfare, and social insecurity. Sociological Forum, vol. 25, no 2, 2010, p. 197-220.

Recebido em Março/2015.

Aprovado em Março/2016. 